\title{
Dental students' uptake of mobile technologies
}

\author{
B. Khatoon, ${ }^{* 1}$ K. B. Hill, ${ }^{1}$ A. D. Walmsley ${ }^{1}$
}
IN BRIEF
- Provides a contemporary insight into the attitude of students towards current technology and tools, and their use in dental education.
- Reveals how dental students are assessing and incorporating mobile apps into their education.
- Describes how dental students use different devices such as smartphones and laptops when accessing information for their undergraduate education.

Aim The aim of this study was to understand how new mobile technologies, such as smartphones and laptops, are used by dental students. Materials and methods A questionnaire was distributed to undergraduate dental students from years 1 to 4, at the University of Birmingham Dental School. Questionnaires were completed between February and April 2013. Results Two hundred and seventy questionnaires were completed. Laptops 55\% (145) and smartphones 34\% (88) were the most popular choice of device for connecting to the net and searching information. Laptops were preferred in first and second year. Students in year 3 preferred mobile phones, and by year 4 the use of mobile phones and laptops was similar. The top two application ideas chosen by students as the most useful on their smart phones were a dictionary for dental education (56\%) and multiple choice questions (50\%). Students who chose smartphones as their first choice or second choice of device strongly agreed that having the Internet on their smartphones had a positive impact on their dental education (55\%). With laptops (48\%), students preferred to be at home when using them while for smartphones (31\%) they used them anywhere with a connection. E-mail (47\%) and social networks (44\%) were the top two Internet communication tools used most on laptops. Instant messaging was popular on smartphones (17\%). Conclusions Depending on the year in the course, laptops and smartphones are the most popular choice of device and desktop computers are the least popular. Applications on smartphones are very popular and instant messaging is an upcoming form of communication for students.

\section{INTRODUCTION}

The Internet has become a popular medium for delivering teaching material, ${ }^{1}$ although its use as a learning tool may only appeal to specific learners. ${ }^{2}$ The Internet is flexible, as students can keep in touch, not only with each other, but also with their tutors through social networks, e-mails, blogging, video conferencing and webcasting. ${ }^{3}$ With the advent of Cloud-computing resources, issues such as memory capacity and processing speeds are no longer seen as a problem to the user as they are external to the mobile device. ${ }^{4}$

Students are generally positive towards the use of information technology. Gupta et al. ${ }^{5}$ found that $79 \%$ of students thought that more computers were needed in their dental school to help them with their learning and that the IT faculties required upgrading.

\footnotetext{
'School of Dentistry, St Chad's Queensway, Birmingham, B4 6NN

${ }^{*}$ Correspondence to: Miss Binish Khatoon

Email: BXK169@bham.ac.uk; Tel: 01214665493
}

\section{Refereed Paper}

Accepted 17 April 2014

DOI: 10.1038/sj.bdj.2014.523

${ }^{\circledR}$ British Dental Journal 2014; 216: 669-673
Although staff had the same opinion about the lack of computer facilities, some teachers expressed the opinion that students did not really use the computers for their studies and were not convinced of their necessity. Students were positive towards web-based teaching compared to their teachers, however, both groups considered it a means of supplementing rather than replacing traditional methods, embracing the idea of blended learning. ${ }^{5}$

As technology evolved the support for online environments such as discussion boards became well established and popular with students. Such discussion boards are not reliant on the technology but more on the interaction within the student discussion room and their teachers. As teachers become more involved with leading the technology, it encourages the student to engage and interact with the discussion. ${ }^{6}$

The increased usage of mobile phones and tablets has provided a previously unrealised ability to move information around quickly and efficiently in a readily available format. The increase in information is not without its drawbacks and learning materials should not only undergo peer review, but also be evidence-based. ${ }^{7}$ Students as learners will always be the drivers of using new technology for their learning needs and this is always evolving, especially with the introduction of mobile devices. While there have been several surveys on the use of the Internet or other specific programmes for dental education, there are limited studies on the present attitudes of students to the use of the newer forms of mobile technology. ${ }^{8,9}$

\section{AIMS}

The aim of this study is to determine the various ways mobile technology is used by dental students in their learning practices within a dental school.

\section{MATERIALS AND METHODS}

From the results of a preliminary pilot study, a structured paper-based questionnaire was developed and distributed during lectures to the first four years out of five at a dental school. It was not possible with the timing of the study to survey the final year students as the survey was done towards the end of the academic year. The results were then manually entered into Survey Monkey. Questions were close ended so students could 
move through the questionnaire quickly. Open-ended questions were included at strategic points in the questionnaire allowing students to provide further comments and reflections about a specific topic or question.

The survey may be found at the following web address: https://www.surveymonkey. com/s/D335XXP

The questionnaire design was based on previous research papers. ${ }^{1,10,11}$ The structure of the questionnaire allowed students to make choices about their preferred devices to access information for personal use or for their dental studies.

\section{RESULTS}

A total of 270 students took part in the questionnaire and the breakdown for gender and age is shown in Table 1. Out of the 270 students, 264 students had regular access to the Internet.

\section{Response rate}

The response rate overall was 100\%. In first year the majority of students were aged 18-19 (56). The majority of students in second year were aged 20-21 (43), with 29 students aged 18-19. In third-year students were predominantly aged 20-21 (49) and in fourth year they were mostly aged between 22-25 (49). Students over 25 were spread throughout as one student was from year 3, one from year 4 and the remaining three from year five.

Over half of the students (55\%) chose laptop as their first choice to access the Internet $(\mathrm{n}=145)$. The second most popular device is smartphones, as 34\% students chose this device as their first choice to access the Internet $(n=88)$.

Over half of the students who chose smartphones as their first or second choice of device strongly agreed that having the Internet on their phones had a positive impact on their studies. iPad/computer tablets and desktop computers were chosen by $8 \%$ and $3 \%$ students respectively. E-book readers were used by 16 students, but their use did not generate positive free text comments, as one student commented that it was seen as a 'device for older people'.

Table 2 shows that the laptops were preferred in years 1 and 2; while year 3 preferred mobile phones. Analysis of year 4 showed that the use of mobile phones and laptops was similar.

As students move through the year groups, the style of usage changes. In the second year there is an equal use of the Internet for their dental course and personal reasons. Compared to these results, the majority of the students from the third and fourth year use the Internet more for personal reasons.

Table 1 The characteristics (age and gender) of the sample of dental students

\begin{tabular}{|l|l|l|l}
\hline Age & Male & Female & Response rate $(\%)$ \\
\hline $18-19$ & 23 & 63 & $32 \%$ \\
\hline $20-21$ & 27 & 86 & $42 \%$ \\
\hline $22-25$ & 23 & 42 & $24 \%$ \\
\hline $25+$ & 1 & 4 & $2 \%$ \\
\hline
\end{tabular}

Table 2 First choice of device to connect to the Internet according to year of study

\begin{tabular}{l|l|l|l|l|l}
\hline Which year of study are you in? & \multicolumn{5}{l}{} \\
\hline $\begin{array}{l}\text { Answer } \\
\text { options }\end{array}$ & 1 & 2 & 3 & 4 & Response (\%) \\
\hline $\begin{array}{l}\text { Laptop } \\
\text { computer }\end{array}$ & 46 & 48 & 22 & 29 & $55 \%$ \\
\hline Smart phone & 12 & 16 & 33 & 27 & $34 \%$ \\
\hline $\begin{array}{l}\text { iPad/computer } \\
\text { tablet }\end{array}$ & 1 & 9 & 3 & 8 & $8 \%$ \\
\hline $\begin{array}{l}\text { Desktop } \\
\text { computer }\end{array}$ & 3 & 2 & 1 & 2 & $3 \%$ \\
\hline
\end{tabular}

Table 3 The most preferred places when connecting to the Internet

\begin{tabular}{|l|l|l}
\hline Answer choice & Laptops \% (n) & Smartphone \% (n) \\
\hline Home & $48 \%(215)$ & $24 \%(106)$ \\
\hline Anywhere with a connection & $14 \%(65)$ & $31 \%(140)$ \\
\hline University/faculty & $25 \%(114)$ & $25 \%(112)$ \\
\hline Library & $13 \%(57)$ & $5 \%(23)$ \\
\hline $\begin{array}{l}\text { Outside of university (coffee } \\
\text { shop, pub etc) }\end{array}$ & $3 \%(15)$ & $10 \%(47)$ \\
\hline Friends' home & $6 \%(29)$ & $4 \%(16)$ \\
\hline Work & $8 \%(17)$ & $2 \%(8)$ \\
\hline Bookstore & $0.4 \%(2)$ & $0.2 \%(1)$ \\
\hline None & 0 & $0 / 2 \%(1)$ \\
\hline Other & 0 & $0.6 \%(3)$
\end{tabular}

Overall, 72\% ( $\mathrm{n}=321)$ students use their device to connect to the Internet at home (Table 3). Furthermore, students using a laptop/ desktop device (48\%) use their device at home more than students with smartphones (24\%). The top two most preferred places for learning with a laptop/desktop computer users were home (48\%) and university/faculty (25\%). For students who use smartphones 'anywhere with a connection' (31\%) and university/ faculty $(25 \%)$ were the top two most preferred places. Other comments included using their smart phone on the 'train' and one student 'while travelling.

The most accessed site by students overall is Google (79\%), followed closely by the internal virtual learning environment at the dental school. Although the option
'University sites' was available, some students specified this with an answer.

While there were no large differences between the devices and the choice of website, $12 \%$ of laptop users compared to $4 \%$ of students with smartphones use Google scholar to access dental subjects. University websites are used more by students through a laptop/desktop (27\%) compared to on smartphones (7\%).

The top two most used Internet communication tools by students on their devices are e-mail (84\%) and social networks (79\%), while blogs $(2 \%)$ and chat rooms (1\%) are the least-used Internet communication tools by students (Table 4).

Instant messaging (23\%) was the third most popular Internet communication 
tool out of the answer choices that were provided to the students.

Students chose 'multiple choice questions' (50\%) and 'Dictionary for dental education' (56\%) as the top choices for apps or web links that they would find useful to access at any time (Table 5).

The third most popular app/web link idea students chose was 'Descriptions and illustrations of tools in dental practice' (32\%). 'Help with PowerPoint presentations and multimedia effects' (3\%) was the least popular idea students selected as an app or web link on their device.

\section{DISCUSSION}

\section{Do you use the Internet more for personal reasons or dental education?}

Students use their devices for personal reasons and for learning dentistry but this can vary between the different years.

Students may be using their personal time at home etc to communicate with tutors and peers about their dental studies. They may define this activity as their personal time rather than dental study time.

Students from year 2 use the Internet roughly an equal amount for dental studies and personal reasons. As students progress to third and fourth year they use the Internet for more personal reasons. This may be due to the enthusiasm students have when they start the course and there is an urge to search for further information on unfamiliar topics. Similar conclusions were made by Fogg et al. ${ }^{11}$

A study in Australia found that students surf the Internet more for pleasure than studies. ${ }^{12}$ Similar findings by KululskaHulme and Petit ${ }^{13}$ show that smartphones are used more for personal use, followed closely by work-related activities.

\section{E-books}

The majority of students did not use E-books, and one student commented that it is for the 'older generation'. These findings should be carefully considered by institutions when considering digitising textbooks.

A previous study revealed that the majority of students did not use E-books as they preferred print books and over the course of the year students had not read a single E-book. ${ }^{14}$

\section{Top choice of devices}

Over 50\% of the students chose the laptop as their first choice of device to connect to the Internet. Mobile learning is an increasing trend within dental education as students prefer smartphones and $\mathrm{iPad} /$ computer tablets.

Table 4 Responses to the top two communication tools students use most on their device

\begin{tabular}{|l|l|l} 
& $\%(\mathrm{n})$ & $\%(\mathrm{n})$ \\
\hline E-mail & $47 \%(206)$ & $30 \%(134)$ \\
\hline Social networks & $44 \%(193)$ & $27 \%(120)$ \\
\hline Instant messaging & $3 \%(15)$ & $17 \%(76)$ \\
\hline Web boards & $2 \%(9)$ & $0.2 \%(1)$ \\
\hline Blogs & $1 \%(6)$ & $0.2 \%(1)$ \\
\hline Chat rooms & $0.6 \% 3)$ & $0.6 \%(3)$ \\
\hline Newsgroups & $1 \%(6)$ & $0.4 \%(2)$ \\
\hline Other & $0.6 \%(3)$ & $0.2 \%(1)$ \\
\hline Answered questions & 225 & 175 \\
\hline
\end{tabular}

Table 5 Applications and web-link ideas that students would find useful on their smartphone to access at any time

\begin{tabular}{|l|l|}
\hline Answer choice & Smartphone \% (n) \\
\hline Dictionary for Dental education & $56 \%(122)$ \\
\hline Multiple choice questions & $50 \%(107)$ \\
\hline Description and illustrations of tools in dental practice & $32 \%(70)$ \\
\hline Help with oral presentations and tests & $23 \%(49)$ \\
\hline Instant messaging/ social networking with fellow students and staff & $16 \%(35)$ \\
\hline Advice for you to give to patients to overcome dental fears & $14 \%(30)$ \\
\hline Stress management for students/staff (yoga app etc) & $11 \%(23)$ \\
\hline Fun activities and games & $9 \%(19)$ \\
\hline Personal portfolio & $7 \%(15)$ \\
\hline Staff contact details and biographies & $6 \%(12)$ \\
\hline Help with PowerPoint presentations and multimedia effects & $3 \%(7)$ \\
\hline None & $3 \%(6)$ \\
\hline Other & $3 \%(6)$ \\
\hline
\end{tabular}

The desktop computer is seen as the least popular method for accessing the Internet. Students are more flexible than previous generations and loyalty to a classic device may be low; students are probably opting for the easiest option and considering the newer gadgets when launched on the market.

Furthermore, the practical benefits of mobile devices may be the reason why students are using them more than desktop computers. For example, students who live away from home may find it difficult to purchase a desktop computer and using a mobile device that they can carry around and use anywhere may be much more practical.

Laptops are personalised with all the work saved on one device and using university computers over laptops may not be the easiest option. Similar results were found by Kinash et $a l .{ }^{14}$ as the majority of students used a smartphone followed closely by laptops.
In comparison, Gosper et al. ${ }^{12}$ recently found that only 13\% students used mobile phones to access information, but 38\% would like to use their phones more in the future to access information.

Previous studies report that dental students would use their devices more often if they were issued with iPads instead of PC laptops. ${ }^{15}$ Another study showed that the strongest interest in using a new device for future coursework was the iPad/tablet. ${ }^{12}$ This may lead to a rise in expectations, as with the introduction of any new device or gadget, that will lead to disappointment if the device does not deliver as its performance suggests. ${ }^{16}$

Although laptops and smartphones are the most used devices among the students in the current study, they may have made different choices if an iPad/tablet was made available to them. The results revealed that students 
from years 1 and 2 are using laptops more, while smartphones are the top choice for students who are in their third year of study.

Fourth-year students chose both laptop computers and smartphones equally. This is interesting as it may be that laptops are a more convenient way to learn as students commence their dental studies, but find mobile learning as a much more convenient format, especially on the clinics.

\section{Most preferred place to search information and learn}

Location is a decisive factor for the choice of device and similar findings were found by Gosper et al. ${ }^{12}$ Thirty-four percent of students are using smartphones from any location and $45 \%$ of students are using laptops at the university campus. This suggests that students are more comfortable to use their laptops in a confined place while sitting down, whereas smartphones may be used anywhere without any restraints. This may be a contributing reason to why there has been a shift from static to mobile devices.

\section{What prevents you from using your device?}

The size of the smartphone is much more convenient for students than laptops, however, the screen view is considerably reduced. The comments that students left for each device show that students are finding it difficult to carry laptop devices and would prefer to leave them at home. One student commented: 'Only use it at home as the laptop is too bulky'.

The importance of both issues for the learning needs of students needs to be further investigated. It was found by Wallace et al. ${ }^{17}$ that among medical students the iPad was likened to carrying around a small textbook and easier to take anywhere with them compared to a laptop, which seemed to be too 'heavy and cumbersome'.

\section{Apps or web links?}

Students who chose smartphones and iPads as their first or second choice of device for searching information were asked to choose what they would find most useful on their devices out of mobile websites and mobile apps. It was found that $48 \%$ students $(n=87)$ for iPads and smartphones would prefer to use mobile websites. This was followed by $37 \%(n=67)$ of students opting for a combination of both websites and apps.

Students wish to access learning resources conveniently using an app (that is, access to local VLE), which is a common finding in other studies. One such example, where the university has regulated apps for student use is the University of Utah. Students have been provided with a number of apps that are anticipated to help students learn about a variety of different topics including human anatomy and 3D images. ${ }^{18}$

\section{YouTube use for dental studies}

Two students commented that YouTube was their top most accessed site for finding information. Interestingly, this was on smartphones only. These comments support a recent study where students felt that when tutors were posting videos on YouTube it gave them a very helpful supplement to the normal teaching methods. Students wanted more teachers to start posting problems and solutions through YouTube videos. ${ }^{15}$

\section{Communication}

Communication in education is key as students value discussion between themselves and their tutors. Table 4 reveals that e-mail and social networking are the most preferred type of communication on a laptop but an increasing level of communication is occurring via instant messaging on smartphones. The increase of this form of communication and its impact on dental education is still unknown and how dentistry as a clinical subject will adapt to such changes requires careful monitoring.

Having a mobile device like a smartphone gives students the extra choices of using instant messages via social networks and software that support instant messaging through the Internet. The popularity of these communication activities reflect upon the growing use of mobile devices for learning, searching for information and now communicating. Instant messaging merits further research. Downloading videos and movies and transferring photos and other data has never been easier as it is on mobile devices. One student commented on smartphones: 'Really good, I take pictures of slides from lectures and flick through them when bored'.

However, one study found that among medical students smartphones are used much more for texting and e-mailing compared to only $10 \%$ using them for transferring photos and images related to patients. ${ }^{17}$

With regards to e-mails, similar results were found when investigating Japanese students' usage of mobile phones for informal learning. It was found that $66 \%$ of students used e-mails to exchange information about lectures. ${ }^{19}$

In the past, blogging was a top choice of communication..$^{10,11,20,21}$ The dramatic decrease in the use of blogs found in this study is related to the increase of easily available social networking apps that do not require the student to keep logging in every time they want to post something online. Similar results are reported by Gosper et al. ${ }^{12}$

Blogging in the past has been labelled as only a personal diary by educators. ${ }^{22}$ The popularity of instant messaging provides easier communication outside the confines of the university. There is a move to 'following' interesting discussion groups, where there is instant feedback to posting. ${ }^{23}$ It is reported that in many cases students are using social networking sites to stay in touch with tutors and fellow students compared to talking to them face to face in the classroom. ${ }^{14}$

The focus of this work was dental students but it is appreciated that they will be entering the workplace, equipped with the newest technology and accessing learning sites with them.

In dentistry, providers of CPD may rapidly find that traditional learning will have to change to mirror the new mobile technologies. For example, the change from desktop computers to mobile devices. A survey on comments left by dentists showed that there are concerns with the privacy aspect of posting information on social networks and the amount of time it will take to ensure that this information is corrected online. ${ }^{24}$

The General Dental Council (GDC) standards document has references to the need for care and professionalism on social networks. ${ }^{25}$ Further research is needed to evaluate the attitudes of students, dentists and tutors and their attitudes to the growing use of social media within dental education and practice.

\section{Useful apps}

There are many app ideas that are utilised by students to support their studies and for searching general information. Students were given a list of ideas to choose from that they would find most useful on their device to access at any time as an app or web link. The three most popular were 'Dictionary for dental education' (70\%), 'Multiple choice questions' (64\%) and 'Description and illustrations of tools in dental education' (39\%).

In a similar process to the recent introduction of the NHS app library, ${ }^{26}$ which lists evidence-based apps, providers of educational material need to be familiar with evidence-based sources of education apps that students may access. The least popular idea was 'Help with PowerPoint presentations and multimedia effects' (6\%). Students may not need assistance and tutoring when using their devices and learning material. One student commented that he/she would like the electronic resources at the University of Birmingham 
to be presented as a downloadable app. This may indicate that students would like to access learning materials at any time and any place via an app or web link on their mobile devices.

Only $16 \%$ of students felt that they would find an app useful that would help them give advice to patients to overcome dental fears. This is an area that requires exploring, as students may well find such an app benefits their approach to patient treatment.

\section{Disadvantages of mobile learning}

Although the majority of comments showed that students have a positive attitude toward mobile learning, there are concerns about being 'distracted' when using mobile devices in the university campuses. One student commented on smartphones:

'Can be useful as available 24-hours-a day, but can be a distraction to my learning'.

Other concerns include relying too much on technology and 'jet skiing' information instead of 'scuba-diving', that is, skimming through material but not reading it in-depth. ${ }^{27}$ It is important too for educators to understand the changing relationship between technology and learning and such approaches require further research. ${ }^{28}$

\section{CONCLUSION}

This study shows that there were differences between student years in their use of mobile devices; initially using laptops and moving towards mobile phone use later in their course.

There is an increase of instant messaging use that cannot be ignored, and future research needs to focus on its effective use within dental education in the most appropriate manner and how dental education can utilise it to better the communication between tutors/practitioners and students.

Such findings mirror the rapid changes in communication technologies and the current generation of dentists will be eager to use their mobile skills in the workplace.

1. Walmsley A D, White D A, Eynon R, Somerfield L. The use of the internet within dental education. Eur J Dent Educ 2003; 7: 27-33.

2. Ess C. Wag the dog? Online conferencing and teaching. Comput Humanities 2000 34: 297-309.

3. Reynolds P A, Mason R, Eaton K A. Remember the days in the old school yard: from lecture to online learning. Br Dent J 2008; 204: 447-451.

4. Kailas A, Chong, C C, Watanabe F. From mobile phones to personal wellness dashboards. IEEE Pulse 2008: 1: 57-63.

5. Gupta B, White D A, Walmsley A D. The attitudes and understanding of undergraduate students and staff to the use of electronic learning. Br Dent J 2004; 196: 487-492.

6. Linjawi A I, Walmsley, A D, Hill K B. Online discussion boards in dental education: potential and challenges. Eur J Dent Educ 2011; 16: e3-e9.

7. Khatoon B, Hill K B, Walmsley A D. Can we learn, teach and practise dentistry anywhere, anytime? Br Dent J 2013 215: 345-347.

8. Reynolds P A, Mason R, Eaton K A. Seeing is believing: dental education benefits from developments in videoconferencing. Br Dent J 2008; 204: 87-91.

9. El-Tantawi MMA. Evaluation of a blog used in dental terminology course for first-year dental students. J Dent Educ 2008; 72: 725-735.

10. Williams J B, Jacobs J. Exploring the use of blogs as learning spaces in the higher education sector. Aust J Educ Tech 2004: 20: 232-247.

11. Fogg L, Phillips L, Baird M, Fogg B. Facebook for educators. Facebook Washington DC, 2011. Online guide available at http://www.scribd.com/ doc/55182215/Facebook-for-Educators-Guide (accessed April 2014)

12. Gosper M, Malfrey J, McKenzie J. Students' experience and expectations of technologies: an Australian study designed to inform planning and development decisions. Austr J Educ Tech 2013; 29: 268-282.

13. Kululska-Hulme A, Pettit J. Practitioners as innovators: emergent practice in personal mobile teaching, learning, work and leisure. In M. Ally (ed) Mobile learning: transforming the delivery of education and training. pp 135-155. Athabasca: Athabasca University Press, 2012.
14. Kinash S, Brand J, Mathew, Trishita. Challenging mobile learning discourse through research: student perceptions of blackboard mobile learn and iPads. Austr J Educ Tech 2011; 28: 683-655.

15. Mayberry J, Hargis J, Boles L et al. Exploring teaching and learning using iTouch mobile device. Active Learning in Higher Education 2012; 13: 203-217.

16. Lou N, Chapman C G, Patel B K et al. Expectations of iPad use in an internal medicine residency program: Is It Worth the "Hype"? J Med Internet Res 2013; 15: e88.

17. Wallace $S$, Clark M, White J. 'It's on my iPhone': attitudes to the use of mobile computing devices in medical education, a mixed-methods study. BMJ Open 2012; 2: ee001099.

18. Wilson, M, Aagard S T. Exposing the gap between what is possible and what is acceptable: How M-learning can make a contribution to sonography education. J Diiagn Med Sonog 2012; 28: 202-206.

19. Thornton $P$, Houser $C$. Using mobile phones in education. In proceeding of the 2 nd IEEE international workshop on wireless and mobile technologies in education, 2004. (WMTE'04) Taiwan.

20. Boulos M N K, Maramba I, Wheeler S. Wikis, blogs, and podcasts: a new generation of web-based tools for virtual collaborative clinical practice and education. BMC Medical Education 2006; 6: 41. Online article available at http://www.biomedcentral. com/1472-6920/6/41 (accessed April 2014).

21. Crook $C$, Fisher T, Graber $R$ et al. Implementing web 2.0 in secondary schools: impacts, barriers, and issues. Becta, 2012. Online article available at http://dera. ioe.ac.uk/1478/1/becta_2008_web2_useinschools report.pdf (accessed April 2014).

22. Wise L. Blogs versus discussion forums in postgraduate online continuing medical education. 2007. Online article available at http://incsub.org/blogtalk/images/ Iwise_blogtalk2005.pdf (accessed April 2014).

23. Oakley, M, Spallek H. Social media in dental education: a call for research and action. J Dent Educ 2012; 76: 279-284.

24. Henry R K, Molnar A, Henry JC. A survey of US dental practices' use of social media. J Contem Dent Prac 2012; 13: 137-141.

25. General Dental Council. Standards for the dental team. London: GDC, 2013. Online standards available at https://www.gdc-uk.org/Dentalprofessionals/ Standards/Pages/standards.aspx (accessed April 2014).

26. NHS Choices Health App Library. Dentify. Online information available at http://apps.nhs.uk/app/ dentifyl (accessed April 2014).

27. Carr N. The shallows: what the internet is doing to our brains. New York: W W. Norton \& Company, 2011.

28. Johnson C A. The information diet: a case for conscious consumption. Sebastapol, CA: O'Reilly Media, 2012 